\title{
Daily ranging patterns of the proboscis monkey, Nasalis larvatus, in coastal areas of Sarawak, Malaysia
}

\section{Manabu Onuma}

\author{
Semenggoh Wildlife Rehabilitation Centre, Sarawak Forestry Department Wisma Sumber Alam, Jalan Stadium, Kuching,
} Sarawak, 93660, Malaysia

The proboscis monkey, Nasalis larvatus, is endemic to Borneo Island. Its main habitats in this region are the mangrove riparian areas and peat swamp forests of the coastal lowlands (Davis 1962; Kern 1964; Kawabe and Mano 1972; Jeffrey 1982). It has been reported that the proboscis monkeys move inland, away from the water's edge (usually rivers) after dawn, and return to the water's edge before dusk (Kern 1964; Kawabe and Mano 1972; Macdonald 1982; Salter et al. 1985; Bennet and Sebastian 1988; Bennet and Gombek 1993). Bennet and Gombek (1993) suggested that returning to riparian areas for the night could be related to the monkeys' social system, in which females move between groups to mate with the fittest male. Gathering at riverbanks offers great opportunities for males to display and for females to meet and assess males of other harems. Others have suggested that these movements reflect predator avoidance (Kern 1964; Jeffrey 1979; Bismark 1981), the proximity of food plants (Bismark 1981) and a suitable place for group reunification (Salter et al. 1985). However, information is scarce on the ranging patterns of the proboscis monkey in coastal regions without large riparian areas.

Salter et al. (1985) reported the daily ranging patterns of the proboscis monkey in Bako National Park, which faces the South China Sea and where there are no large rivers. At that site, monkeys moved to the water's edge (a brackish mangrove forest) during the day and returned inland to a mixed dipterocarp/high kerangas forest at night. However, the authors located proboscis monkeys by scanning from elevated viewpoints along the coast, and did not follow specific individuals or harems. Therefore, they could not accurately determine the extent of daily or long-term movements of individual proboscis monkeys in the park, raising the possibility that other ranging patterns may be occurring.

Some park rangers also suggested that the monkeys use the mangrove forest during low tide. Because there is a $30 \mathrm{~m}$ wide intertidal zone with no vegetation between the land and the brackish mangrove forest used by the monkeys at the study site, they would need to swim to reach the mangrove forest during high tide. Consequently, tidal level might also affect the movement of proboscis monkeys in the park.

In the present study, I attached a radio transmitter to a female proboscis monkey to track her location and review the daily movement of proboscis monkeys in Bako National Park. In addition, I assessed the effects of tidal level on the monkeys' daily ranging patterns.

\section{Materials and methods}

The study was conducted in 1997 within Bako National Park, in the state of Sarawak, Malaysia, approximately $20 \mathrm{~km}$ northeast of Kuching, the state capital. The site is primarily hilly land, rising from sea level to approximately $100 \mathrm{~m}$. A mixed dipterocarp/high kerangas forest occurs up to approximately $80 \mathrm{~m}$ above sea level, and an open scrub/fire padang occupies a promontory plateau. A mangrove forest exists at the foot of the promontory and there is a $30 \mathrm{~m}$ wide intertidal zone with no vegetation between the foot of the promontory and the mangrove forest (Fig. 2).

A female proboscis monkey $(4.8 \mathrm{~kg})$ was caught by a fisherman at Bako village, adjacent to the national park, when she was swimming across the Bako River on 25 June. Prior to releasing the monkey back into the wild, a radio transmitter (MOD-080, TELONICS Inc., Arizona, USA) was attached to her back. The transmitter was

E-mail: sunbear@vetmed.hokudai.ac.jp Present address: Laboratory of Wildlife Biology, Graduate School of Veterinary Medicine, Hokkaido University, N18 W9 Kita-ku, Sapporo, Hokkaido 060-0810, Japan 
Time of the day

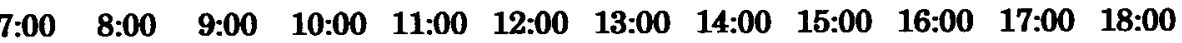

\begin{tabular}{|c|c|c|c|c|c|c|c|c|c|c|c|c|c|}
\hline Jun. 27 & & & & Relear & & . & & & & & & & \\
\hline Jul. 2 & * & & & & & & & & & & & & \\
\hline Jul. 5 & & & & & & & & $\mathrm{O}$ & & & & & \\
\hline Jul. 12 & & & & & & 0 & 0 & 0 & & & & & \\
\hline Jul. 15 & $*$ & & & & & & & & 0 & 0 & $x$ & 0 & 0 \\
\hline Jul. 16 & & 0 & 0 & 0 & 0 & $\mathrm{x}$ & 0 & & & & & & \\
\hline Jul 19 & & & & & 0 & 0 & 0 & 0 & & & & & \\
\hline Jul. 24 & & & & 0 & 0 & 0 & 0 & 0 & 0 & 0 & & & \\
\hline Aug. 2 & $*$ & & & & & & 0 & 0 & 0 & 9 & & & \\
\hline Aug. 9 & & & & & & 0 & $X$ & $\mathrm{X}$ & $\mathrm{X}$ & 0 & & & \\
\hline Aug. 10 & $*$ & & & & & & & & & & & & \\
\hline Aug. 13 & & & & & & 0 & 0 & 0 & 0 & & & & \\
\hline Aug. 23 & & & & & 0 & 0 & 0 & 0 & 0 & 0 & 0 & & \\
\hline Aug. 29 & $*$ & & & & & & & & & & & & \\
\hline Aug. 30 & & & & & & & 0 & 0 & - & - & & & \\
\hline Sep. 6 & & & & & & & 0 & 0 & 0 & 0 & & & \\
\hline Sep. 12 & & & & Trans & tter & retri & & & & & & & \\
\hline
\end{tabular}

Fig. 1. Location data points $(n=49)$ collected over 12 days during the observation period. Open circles $(O)$ indicate location data collected during low tide and solid circles $(O)$ indicate those collected during high tide. Crosses $(X)$ indicate that location data could not be obtained due to weather. Asterisks (*) indicate the dates that the harem was directly observed. Direct observations alone were conducted on 10 and 29 August 1997.

equipped with a mortality sensor that decreases transmitter pulse frequency when kept in the same location for five hours.

During the study period, I radio-tracked the monkey at hourly intervals from a natural trail at the foot of the promontory, usually from a distance of $<400 \mathrm{~m}$, and estimated the monkey's location using the triangulation method (White and Garott 1990). The elevation of each location was used as an index of her daily movement because the monkeys used both the mangrove forest in the tidal zone and the mixed dipterocarp/high kerangas forest on a steep cliff. Data collected during the first week (27 June to 4 July) was not used for analysis, to ensure that the monkey had adjusted to the radio and to being tracked. The range covered by the monkey during the study period was calculated using the minimum convex polygon method (Mohr 1947).

I recorded tidal level (high or low) each time the monkey was located. High tide was defined as when the entire floor of the mangrove forest and the intertidal zone were completely covered by seawater, and low tide was defined as when part of the intertidal zone was exposed.

On 26 June the monkey was released in Bako National Park. On 2 July, I observed her with a harem comprised of one male and five females. Some of the park rangers and I saw her in the same harem on 15 July and 2, 10 and 29 August. Therefore, I assumed that the movement of the female monkey represented that of the entire harem and that she did not move between harems during the study period. On 12 September the mortality sensor was activated and the transmitter was retrieved but there was no carcass in the vicinity of the transmitter. The study was terminated at this time.

\section{Results and discussion}

Following the initial adjustment period, I attempted to locate the monkey on 54 occasions during 54 hours over 12 days, from 5 July to 6 September 1997 (Fig. 1). I could not obtain the location data on five occasions due to weather on 15 and 16 July and 9 August. Hence, data from 49 locations were used for the analyses (Fig. 2).

The distribution of the locations indicated that the harem moved throughout both the coastal mangrove and inland forests. They climbed steep cliffs, up to $90 \mathrm{~m}$ above sea level, and moved up to $400 \mathrm{~m}$ inland, covering an area of approximately $0.3 \mathrm{~km}^{2}$.

Two ranging patterns associated with tidal levels were 


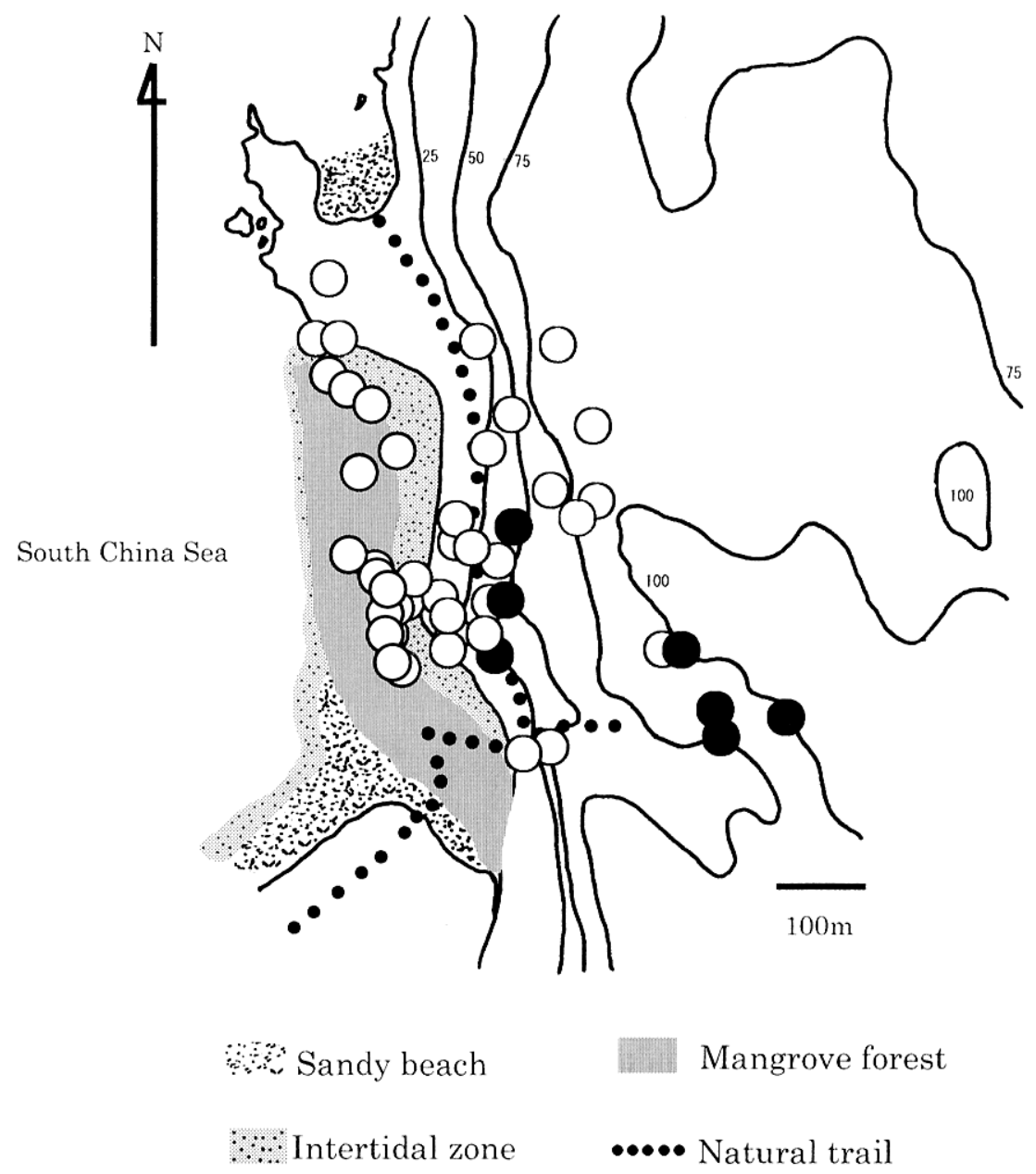

Fig. 2. Locations $(n=49)$ of the radio-tracked proboscis monkey after her release. The circles (open or solid) are the same as for Fig. 1.

apparent (Fig. 3a, b). When low tide occurred during the day, the harem moved to the mangrove forest along the coast, returned inland before dusk, and stayed in the mixed dipterocarp/high kerangas forest, approximately $70 \mathrm{~m}$ above sea level, overnight. This daily ranging pattern was similar to that reported by Salter et al. (1985) (Fig. 3a). Conversely, the monkeys stayed in the mixed dipterocarp/high kerangas forest (inland) when high tide occurred during the day (Fig. 3b).

Proboscis monkeys are known to swim frequently. It is unclear why they avoided swimming between the land and the mangrove forest during day-time high tide. One possibility is the presence of estuarine crocodiles (Crocodylus porosus) that are potential predators of the proboscis monkey (Bennet and Gombek 1993). The presence of crocodiles in the area was confirmed by an accidental catch in a fishing-net near the park. It is likely that the crocodiles enter the mangrove forest together with the inflow of seawater. However, the location data during high tide were obtained only eight times over four days. Long-term observations are needed at Bako National Park, or other coastal areas without a large river, to further explain the effects of tidal levels on the daily ranging pattern of proboscis monkeys.

It has been reported that proboscis monkeys tend to roost at water's edge (Kern 1964; Kawabe and Mano 1972; Macdonald 1982; Salter et al. 1985; Bennet and Sebastian 1988; Bennet and Gombek 1993). However, in the present study proboscis monkeys selected inland forests $70 \mathrm{~m}$ above sea level for nighttime roosts. The result is consistent with Salter et al. (1985), who reported that monkeys gathered in tall trees in the park's forest. In addition, Jeffrey (1982) reported that monkeys roosted at cliff edges in Kalimantan. These results suggest that roosting at water's edge might not be a consistent behavior among proboscis monkeys.

Roosting site selection may depend on features common to both the inland habitat in Bako National Park and 

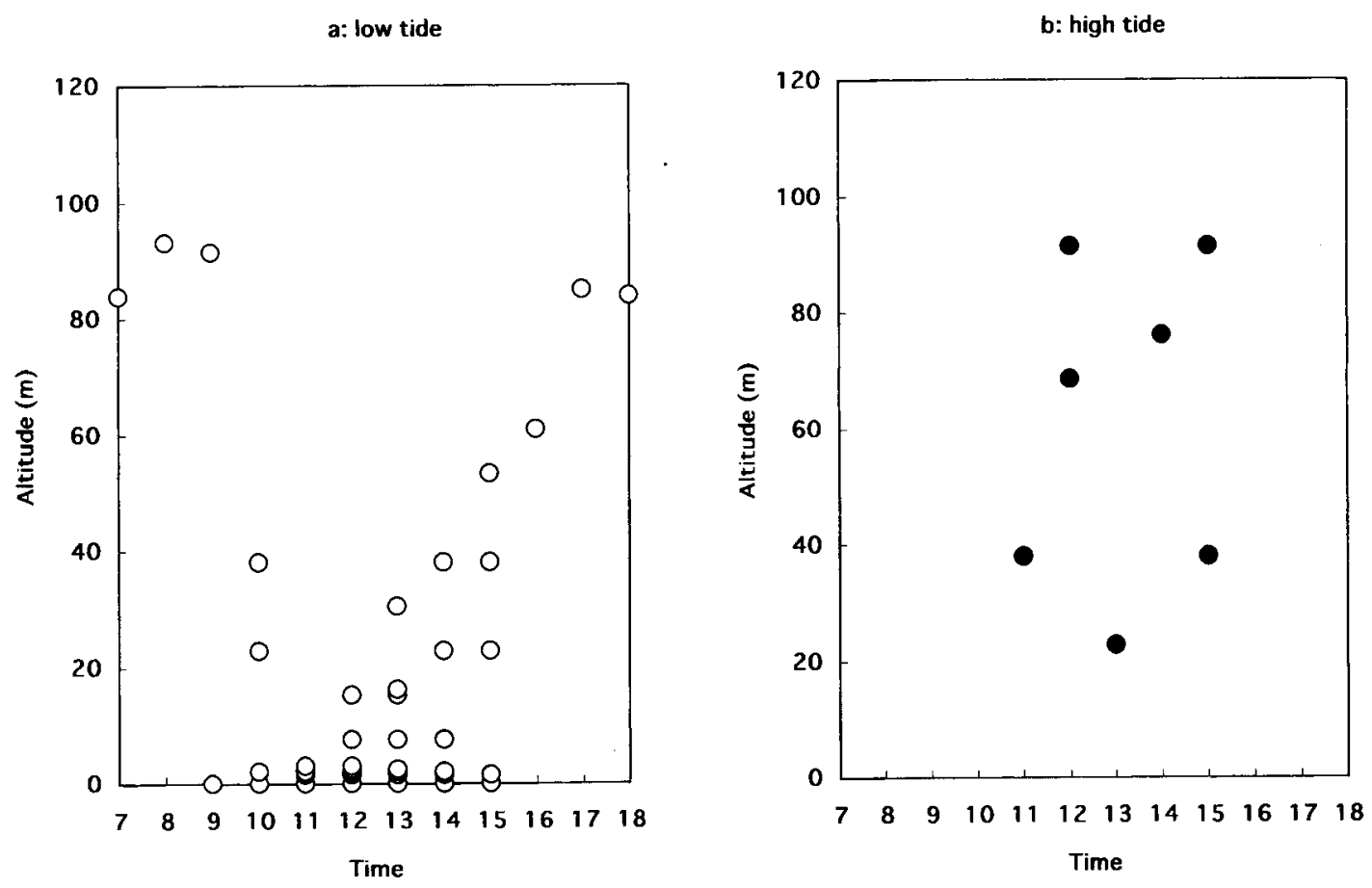

Fig. 3. Daily ranging patterns of proboscis monkeys in Bako National Park.

the riparian habitats in other areas such as Samunsam Wildlife Sanctuary. For example, roosts in both inland and riparian habitat may provide proboscis monkeys with relatively uncluttered views of surrounding areas, a benefit for avoiding predation (Kern 1964; Jeffrey 1979; Bismark 1981) and/or to display (Bennet and Gombek 1993). More detailed assessments of roost site and other habitat characteristics are needed to test this hypothesis.

Acknowledgements: This study was funded by the Sarawak Forestry Department, KPU0003 (the fund for wildlife rehabilitation). I give special thanks to Encik Sapuan Hj. Ahmad and Mr. Oswald Braken Tisen for their assistance in this study. I also thank Encik Azahari, the officer in charge of Bako National Park, and other Park staff for their kind support, as well as Dr. E. L. Bennet, who provided useful information about proboscis monkeys. Encik Abg. Motalib's help was essential to this research. Finally, I thank Dr. Noriyuki Ohtaishi and Dr. Masatsugu Suzuki for providing helpful comments and advice regarding this manuscript.

\section{References}

Bennett, E. L. and Sebastian, A. C. 1988. Social organization and ecology of proboscis monkeys (Nasalis larvatus) in mixed coastal forest in Sarawak. International Journal of Primatology 9: 233255.

Bennett, E. L. and Gombek, F. 1993. Proboscis Monkeys of Borneo. Natural History Publications (Borneo) Sdn. Bhd. \& KOKTAS Sabah Berhad, Sabah, 75 pp.

Bismark, M. 1981. Preliminary survey of the proboscis monkey at Tanjung Putting Reserve, Kalimantan. Tigerpaper 8: 26.

Davis, D. D. 1962. Mammals of the lowland rain forests of North Borneo. Bulletin of National Museum Singapore 31: 1-129.

Jeffrey, S. M. 1979 . The proboscis monkey, some preliminary observations. Tigerpaper 6: 5-6.

Jeffrey, S. M. 1982. Threats to the proboscis monkey. Oryx 16: 337339.

Kawabe, M. and Mano, T. 1972. Ecology and behavior of the wild proboscis monkey, Nasalis larvatus (Wurm) in Sabah, Malaysia. Primates 13: 213-227.

Kern, J. A. 1964. Observations on the habits of the proboscis monkey, Nasalis larvatus (Wurmb), made in the Brunei Bay area, Borneo. Zoologica 49: 183-191.

Macdonald, D. W. 1982. Notes on the size and composition of groups of proboscis monkey (Nasalis larvatus). Folia Primatologica 37: 95-98.

Mohr, C. O. 1947. Table of equivalent populations of North American small mammals. American Midland Naturalist 37: 223-249.

Salter, R. E., Mackenzie, N. A., Nightingale, N., Aken, K. M. and Chai, P. P. K. 1985. Habitat use, ranging behaviour, and food habits of the proboscis monkey, Nasalis larvatus (van Wurmb), in Sarawak. Primates 26: 436-451.

White, G. C. and Garott, R. A. 1990. Estimating animal locations. In Analysis of Wildlife Radio-Tracking Data. Pp. 41-78. Academic Press, San Diego.

Received 7 February 2002. Accepted 4 September 2002. 